Pacific Journal of Mathematics

ON A FIXED POINT THEOREM OF KRASNOSELSKII FOR P. P. Sw o 


\title{
ON A FIXED POINT THEOREM OF KRASNOSELSKII FOR LOCALLY CONVEX SPACES
}

\author{
V. M. Sehgal and S. P. Singh
}

\begin{abstract}
Let $\mathcal{U}$ be a neighborhood basis of the origin consisting of absolutely convex open subsets of a separated locally convex topological vector space $E$ and $S$ a subset of $E$. Let a mapping $f: S \rightarrow E$ satisfy the condition: for each $U \in \mathcal{U}$ and $\epsilon>0$, there exists a $\delta=\delta(\epsilon, U)>0$ such that if $x, y \in S$ and $x-y \in(\epsilon+\delta) U$, then $f(x)-f(y) \in \epsilon U$. In the present paper, sufficient conditions are given for the mapping $f$ to have a fixed point in $S$. The result is extended to the sum of two mappings of Krasnoselskii type.
\end{abstract}

In a recent paper, Meir and Keeler [8] gave an interesting generalization of the Banach's contraction principle. Following [8], a self mapping $f$ of a metric space $(X, d)$ is an $(\epsilon, \delta)$ contraction iff for each $\epsilon>0$ there exists a $\delta=\delta(\epsilon)>0$ such that for all $x, y \in X$ with $\epsilon \leqq$ $d(x, y) \leqq \epsilon+\delta$ implies $d(f(x), f(y))<\epsilon$. The $(\epsilon, \delta)$ contraction mappings clearly contain the class of strict contractions $(d(f(x), f(y)) \leqq$ $\lambda d(x, y), 0<\lambda<1)$ and the nonlinear contractions investigated by Boyd and Wong [4]. In this paper, we consider mappings defined on a subset $S$ of a locally convex vector space $E$ with values in $E$ (not necessarily $S$ ) and satisfy a certain condition similar to $(\epsilon, \delta)$ contraction. The main result here generalizes a result of Cain and Nashed [5] and a recent result of Assad and Kirk [2] and provides a further generalization of a well-known result of Krasnoselskii [7].

Throughout this paper, $E$ is a separated locally convex topological vector space and $\mathcal{U}$ is a neighborhood basis of the origin consisting of absolutely convex open subsets of $E$. For each $U \in \mathcal{U}$, let $p_{U}$ be the Minkowski's functional of $U$. Further, if $x, y \in E$ let

$$
(x, y)=\{z \in E: z=\lambda x+(1-\lambda) y, 0<\lambda<1\}
$$

and $[x, y),=\{x\} \cup(x, y)$. For a set $A \subseteq E, \partial(A)$ denotes the boundary of $A$ and $\operatorname{cl}(A)$ the closure of $A$ in $E$. Also for $A, B \subseteq E, A-B=$ $\{x-y: x \in A, y \in B\}$.

Let $S$ be a nonempty subset of $E$. A mapping $f: S \rightarrow E$ is a $U$-contraction $(U \in \mathcal{U})$ iff for each $\epsilon>0$ there is a $\delta=\delta(\epsilon, U)>0$ such that if $x, y \in S$ and if

$$
x-y \in(\epsilon+\delta) U, \text { then } f(x)-f(y) \in \epsilon U \text {. }
$$


If $f: S \rightarrow E$ is a $U$-contraction for each $U \in \mathcal{U}$, then $f$ is a $U$-contraction. Note that if $f$ is a $U$-contraction, then $f$ is continuous. (For a related definition of $U$-contraction, see Taylor [11].)

It may be remarked that if $E$ is a normed space with $U=$ $\{x \in E:\|x\|<\epsilon, \epsilon>0\}$ then (1) is equivalent to $(\epsilon, \delta)$ contraction [8].

The following lemma simplifies the proof of next theorem.

Lemma 1. Let $f: S \rightarrow E$ be a $U$-contraction, then $f$ is $U$-contractive, that is for each $U \in \mathcal{U}, p_{U}(f(x)-f(y))<p_{U}(x-y)$ if $p_{U}(x-y) \neq 0$ and 0 otherwise.

Proof. Let $x, y \in S$ and suppose $p=p_{U}, p(x-y)=\epsilon>0$. Then $x-y \in(\epsilon+\delta) U$ for each $\delta>0$ and in particular $x-y \in\left(\epsilon+\delta_{0}\right) U$ where $\delta_{0}=\delta(U, \epsilon)$. Therefore by $(1)(f(x)-f(y)) \in \epsilon U$. Since $U$ is open, this implies that $p(f(x)-f(y))<\epsilon=p(x-y)$. If $\epsilon=0$, then $x-y \in \epsilon U$ for each $\epsilon>0$ and hence by (1) $(f(x)-f(y)) \in \epsilon U$ which implies that $p(f(x)-f(y))=0$.

THEOREM 1. Let $S$ be a sequentially complete subset of $E$ and $f: S \rightarrow E$ be a $\mathcal{U}$-contraction. If $f$ satisfies the condition:

for each $x \in S$ with $f(x) \notin S$, there is a $z \in(x, f(x)) \cap S$ such that $f(z) \in S$

then $f$ has a unique fixed point in $S$.

Proof. Let $x_{0} \in S$ and choose a sequence $\left\{x_{n}\right\} \subseteq S$ defined inductively as follows: for each $n \in I$ (positive integers) if $f\left(x_{n}\right) \in S$, set $x_{n+1}=f\left(x_{n}\right)$ and if $f\left(x_{n}\right) \notin S$, let $x_{n+1}$ be any element of $\left(x_{n}, f\left(x_{n}\right)\right) \cap S$ such that $f\left(x_{n+1}\right) \in S$ (such $x_{n+1}$ exists by (2)). It then follows that for each $n \in I$, there is a $\lambda_{n} \in[0,1)$ satisfying

$$
x_{n+1}=\lambda_{n} x_{n}+\left(1-\lambda_{n}\right) f\left(x_{n}\right) \text {. }
$$

We show that the sequence $\left\{x_{n}\right\}$ so constructed satisfies
(a) $x_{n+1}-x_{n} \rightarrow 0$
(b) $x_{n}-f\left(x_{n}\right) \rightarrow 0$

To establish (4), note that by (3)

$$
\begin{gathered}
x_{n+1}-x_{n}=\left(1-\lambda_{n}\right)\left(f\left(x_{n}\right)-x_{n}\right), \quad \text { and } \\
f\left(x_{n}\right)-x_{n+1}=\lambda_{n}\left(f\left(x_{n}\right)-x_{n}\right) .
\end{gathered}
$$

Therefore, for a $U \in \mathcal{U}$ with $p=p_{U}$, it follows by the above lemma that 


$$
\begin{aligned}
p\left(f\left(x_{n+1}\right)-x_{n+1}\right) & \leqq p\left(f\left(x_{n+1}\right)-f\left(x_{n}\right)\right)+p\left(f\left(x_{n}\right)-x_{n+1}\right) \\
& \leqq p\left(x_{n+1}-x_{n}\right)+\lambda_{n}\left(f\left(x_{n}\right)-x_{n}\right)
\end{aligned}
$$

Thus by (5) $p\left(f\left(x_{n+1}\right)-x_{n+1}\right) \leqq p\left(f\left(x_{n}\right)-x_{n}\right)$ for each $n \in I$, that is $\left\{p\left(f\left(x_{n}\right)-x_{n}\right)\right\}$ is a nonincreasing sequence of nonnegative reals and hence for each $p=p_{U}, U \in \mathcal{U}$, there is a $r(\dot{U}) \geqq 0$ with

$$
r(U) \leqq p\left(f\left(x_{n}\right)-x_{n}\right) \rightarrow r(U) \geqq 0 .
$$

We claim that $r(U) \equiv 0$. Suppose $r(U)>0$. Choose a $\delta=$ $\delta(r(U), U)>0$ satisfying (1). Then by (7) there is a $n_{0} \in I$ such that $p\left(f\left(x_{n}\right)-x_{n}\right)<r(U)+\delta$ for all $n \geqq n_{0}$. Now choose an $m \in I, m \geqq n_{0}$ such that $x_{m+1}=f\left(x_{m}\right)$, (let $m=n_{0}$ if $f\left(x_{n_{0}}\right) \in S$, otherwise let $m=n_{0}+1$, then $\left.x_{m+1}=f\left(x_{m}\right) \in S\right)$. Thus for this $m$,

$$
p\left(x_{m}-x_{m+1}\right)=p\left(x_{m}-f\left(x_{m}\right)\right)<r(U)+\delta .
$$

and hence by (1)

$$
p\left(x_{m+1}-f\left(x_{m+1}\right)\right)=p\left(f\left(x_{m}\right)-f\left(x_{m+1}\right)\right)<r(U),
$$

which contradicts (7). Thus $r(U)=0$ for each $U \in U$ and this implies that the sequence $x_{n}-f\left(x_{n}\right) \rightarrow 0$. This establishes 4(b) and 4(a) now, follows by (5).

We assert that $\left\{x_{n}\right\}$ is a Cauchy sequence in $E$. Suppose not. Let for each $k \in I, A_{k}=\left\{x_{n}: n \geqq k\right\}$. Then by assumption there is $U \in \mathcal{U}$ such that $A_{k}-A_{k} \notin E U$ for any $k \in I$. Choose an $\epsilon$ with $0<\epsilon<1$ and a $\delta$ with $0<\delta<\delta(\epsilon, U)$ satisfying $\epsilon+\delta<1$. It follows that $A_{k}-A_{k} \not \subset(\epsilon+\delta / 2) U$ for any $k \in I$. Thus for each $k \in I$, there exist integers $n(k)$ and $m(k)$ with $k \leqq n(k)<m(k)$ such that

$$
x_{n(k)}-x_{m(k)} \notin(\epsilon+\delta / 2) U \text {. }
$$

Let $m(k)$ be the least integer exceeding $n(k)$ satisfying (8). Then by (8)

$$
\begin{aligned}
x_{n(k)}-x_{m(k)}= & \left(x_{n(k)}-x_{m(k)-1}\right)+\left(x_{m(k)-1}-x_{m(k)}\right) \\
& \in\left(x_{m(k)-1}-x_{m(k)}\right)+(\epsilon+\delta / 2) U .
\end{aligned}
$$

Now by (4) there is a $k_{0} \in I$ such that $x_{k}-f\left(x_{k}\right) \in(\delta / 4) U$ and $x_{k-1}-x_{k} \in$ $(\delta / 4) U$ whenever $k \geqq k_{0}$, and hence by (9)

$$
x_{n(k)}-x_{m(k)} \subseteq(\epsilon+\delta) U, \quad k \geqq k_{0} .
$$

It follows, that for all $k \geqq k_{0}$ 


$$
f\left(x_{n(k)}\right)-f\left(x_{m(k)}\right) \in \epsilon U \text {. }
$$

However, for $k \geqq k_{0}$,

$$
x_{n(k)}-x_{m(k)}=\left(x_{n(k)}-f\left(x_{n(k)}\right)\right)+\left(f\left(x_{n(k)}\right)-f\left(x_{m(k)}\right)\right)+\left(f\left(x_{m(k)}\right)-x_{m(k)}\right)
$$

and therefore,

$$
x_{n(k)}-x_{m(k)} \in\left(\frac{\delta}{4} U+\epsilon U+\frac{\delta}{4} U\right) \subseteq\left(\epsilon+\frac{\delta}{2}\right) U, \quad k \geqq k_{0},
$$

which contradicts (8). Thus $\left\{x_{n}\right\}$ is a Cauchy sequence in $S$ and the sequential completeness implies that there is a $u \in S$ such that $x_{n} \rightarrow u$. Since $f$ is continuous, it follows by (4b) that $u=f(u)$. This proves the existence of the fixed point of $f$. Since $E$ is separated, the uniquencess is an immediate consequence of the Lemma 1.

The following result was proven in [10] and its proof here is given for completeness.

LEMMA 2. Let $S$ be a closed or sequentially complete subset of $E$. If $x \in S$ and $y \notin S$ then there is a $\lambda \in[0,1]$ such that $z=$ $(1-\lambda) x+\lambda y \in \partial(S)$. Further, if $x \notin \partial(S)$ then $0<\lambda<1$.

Proof. Let $A=\{\mu \geqq 0:(1-\alpha) x+\alpha y \in S$ for all $\alpha$ with $0 \leqq \alpha \leqq$ $\mu\}$. Since $x \in S, A \neq \varnothing$. The hypothesis $y \notin S$ implies that $\lambda=$ $\sup \{\mu: \mu \in A\} \leqq 1$. Now if $S$ is closed or sequentially complete, it follows that $z=(1-\lambda) x+\lambda y \in S$ and hence $\lambda<1$. To show that $z \in \partial(S)$, it suffices to show that for each $U \in \mathcal{U},(z+U) \cap c(S) \neq \varnothing$, where $c(S)$ is the complement of $S$ in $E$. Choose a $\beta_{0}>\lambda$ with $\left(\beta_{0}-\lambda\right) p(x-y)<1$ where $p=p_{U}$. By definition of $\lambda$, there is a $\beta$ with $\lambda<\beta \leqq \beta_{0} \quad$ such that $z_{1}=(1-\beta) x+\beta y \notin S$. Since $p\left(z-z_{1}\right)=$ $(\beta-\lambda) p(x-y)<1$, it follows that $z_{1} \in(z+U)$ and hence $z \in \partial(S)$. If $x \notin \partial(S)$ but $x \in S$, then clearly $0<\lambda<1$.

The following is now an immediate consequence of Theorem 1.

THEOREM 2. Let $S$ be sequentially complete subset of $E$ and $f: S \rightarrow E$ be a $U$-contraction. If $f(S \cap \partial(S)) \subseteq S$, then $f$ has a unique fixed point.

It may be noted that if $S$ is closed then $S \cap \partial(S)=\partial(S)$.

In the following, let $\mathscr{P}=\left\{p=p_{U}\right.$ for some $\left.U \in \mathscr{U}\right\}, R^{+}$the nonnegative reals and $\Psi$ a family of mappings defined as $\Psi=\left\{\phi: R^{+} \rightarrow R^{+}: \phi\right.$ is continuous and $\phi(t)<t$ if $t>0\}$. A mapping $f: S \rightarrow E$ is a nonlinear $\mathscr{P}$ contraction (see also Boyd and Wong [4]) iff for each $p \in \mathscr{P}$, there is a $\phi_{p} \in \Psi$ such that $p(f(x)-f(y)) \leqq \phi_{p}(p(x-y))$ for all $x, y \in S$. If this 
inequality holds with $\phi_{p}(t)=\alpha_{p} t, 0<\alpha_{p}<1$, then $f$ is called $\mathscr{P}$ contraction (see [5]). Since a nonlinear $\mathscr{P}$ contraction is a $\mathcal{U}$ contraction, the following result immediately follows by Theorem 1 and provides an extension of a result in [5], (see also Assad [1]).

THEOREM 3. Let $S$ be a sequentially complete subset of $E$ and $f: S \rightarrow E$ be a nonlinear $\mathscr{P}$ contraction. If $f$ satisfies (2) then $f$ has a unique fixed point in $S$.

As an application of Theorem 3, we give here a generalization of a well-known result of Krasnoselskii [7] which has been extended recently to locally convex spaces in [5]. The following extension of Tychonoff's theorem [12] is due to Singball [3] (see also Himmelberg [6]) and is used in the proof of Theorem 5 .

THEOREM 4. Let $S$ be a closed and convex subset of $E$ and $f: S \rightarrow S$ be a continuous mapping such that the range $f(S)$ is contained in a compact set. Then $f$ has fixed point.

In the rest of this paper, a mapping $f: S \rightarrow E$ is completely continuous if it is continuous and $f(S)$ is contained in a compact subset of $E$. Further, if $A: S \rightarrow E$ is a nonlinear $\mathscr{P}$ contraction and $B: S \rightarrow E$ is completely continuous, then for each fixed $x \in S$, the mapping $f_{x}: S \rightarrow E$ is defined by $f_{x}(y) \Rightarrow A(y)+B(x)$. Note that since $E$ is separated, the mapping $(I-A): S \rightarrow E$ is one-to-one, where $I$ is the identity map of $S$.

The following lemma follows immediately from Theorem 3.

LEMMA 3. Let $S$ be a sequentially complete subset of $E$ and $A: S \rightarrow E$ be a nonlinear $\mathscr{P}$ contraction. Suppose for $a x \in E$, the mapping $f: S \rightarrow E$ defined by $f(y)=A(y)+x$ satisfies (2), then there exists a unique $u(x) \in S$ with $f(u(x))=u(x)$, that is $(I-A)^{-1} x=$ $u(x) \in S$.

THEOREM 5. Let $S$ be a convex and complete subset of E. Let $A: S \rightarrow E$ be a nonlinear $\mathscr{P}$ contraction and $B: S \rightarrow E$ be completely continuous. If for each $x \in S$, the mapping $f_{x}: S \rightarrow E$ satisfies (2) and $(I-A)^{-1} B(S)$ is a bounded subset of $S$, then there is a $u \in S$ satisfying $A(u)+B(u)=u$.

Proof. For each fixed $x \in S$, the mapping $f_{x}$ satisfies the conditions of Lemma 3 and hence there is a unique $u_{x} \in S$ with $f_{x}\left(u_{x}\right)=u_{x}$. Define a mapping $L: S \rightarrow S$ by

$$
L(x)=u_{x}=A(L(x))+B(x), \quad x \in S .
$$


Then, for each $x \in S, L(x)=(I-A)^{-1} B(x)$. If follows by hypothesis that $L(S)$ is a bounded subset of $E$. We show that $L$ in (10) is continuous. Let $\left\{x_{\alpha}: \alpha \in \Gamma\right\} \subseteq S$ be a net such that $x_{\alpha} \rightarrow x \in S$ and suppose $L\left(x_{\alpha}\right)$ does not converge to $L(x)$. Then there is a $p \in \mathscr{P}$ and an $\epsilon>0$ and a subnet $\left\{p\left(L\left(x_{\alpha}\right)-L(x)\right): \alpha \in \Gamma_{1}\right\}$ of the net $\left\{p\left(L\left(x_{\alpha}\right)-L(x)\right): \alpha \in \Gamma\right\}$ such that

$$
p\left(L\left(x_{\alpha}\right)-L(x)\right)>\epsilon \quad \text { for each } \quad \alpha \in \Gamma_{1} .
$$

Since $\left\{p\left(L\left(x_{\alpha}\right)-L(x)\right): \alpha \in \Gamma_{1}\right\}$ is a bounded subset of the reals, it has a subnet $\left\{p\left(L\left(x_{\alpha}\right)-L(x)\right): \alpha \in \Gamma_{2} \subseteq \Gamma_{1}\right\} \rightarrow r \geqq 0$. However, by (10) for any $\alpha \in \Gamma_{2}$

$$
p\left(L\left(x_{\alpha}\right)-L(x)\right) \leqq p\left(B\left(x_{\alpha}\right)-B(x)\right)+\phi_{p}\left(p\left(L\left(x_{\alpha}\right)-L(x)\right)\right),
$$

which implies that $r=0$. This contradicts (11) and consequently $L$ is continuous. We now show that $L(S)$ is relatively compact in $S$. If $\left\{L\left(x_{\alpha}\right): \alpha \in \Gamma\right\}$ is a net in $L(S)$, then there is a net $\left\{B\left(x_{\alpha}\right): \alpha \in \Gamma_{1}\right\}$ which is convergent. We assert that $\left\{L\left(x_{\alpha}\right): \alpha \in \Gamma_{1}\right\}$ is a Cauchy subnet. Suppose not. Then there is a $p \in \mathscr{P}$ and an $\epsilon>0$ such that for each $\alpha \in \Gamma_{1}$ there are elements $n(\alpha)$ and $m(\alpha)$ in $\Gamma_{1}$ with $n(\alpha) \geqq \alpha$, $m(\alpha) \geqq \alpha$, satisfying

$$
r_{\alpha}=p\left(L\left(x_{n(\alpha)}\right)-L\left(x_{m(\alpha)}\right)\right)>\epsilon, \quad \alpha \in \Gamma_{1} .
$$

Since $\left\{B\left(x_{\alpha}\right): \alpha \in \Gamma_{1}\right\}$ is a Cauchy net, there is an $\alpha_{0} \in \Gamma_{1}$ such that $p\left(B\left(x_{\alpha}\right)-B\left(x_{\beta}\right)\right)<\epsilon$ for all $\alpha, \beta \geqq \alpha_{0}, \alpha, \beta \in \Gamma_{1}$. However, $\left\{r_{\alpha}: \alpha \in \Gamma_{1}\right\}$ being a bounded subset of reals has a convergent subnet $\left\{r_{\alpha}: \alpha \in \Gamma_{2}\right\}$ $\rightarrow r \geqq 0$. The same argument as above implies that $r=0$ and this contradicts (12). This proves the assertion. It now follows by Theorem 4 , that $L(u)=u$ for some $u \in S$ and hence by $(10) A(u)+B(u)=u$.

The following consequence of Theorem 5 appears new and generalizes a result of Nashed and Wong (Theorem 1 [9]). Note that in a normed linear space $E$ a mapping $f: S \rightarrow E$ is a nonlinear contraction (see [4]) if there exists a $\phi \in \Psi$ such that $\|f(x)-f(y)\| \leqq \phi(\|x-y\|)$ for all $x, y \in S$.

Corollary 1. Let $S$ be a closed, bounded and convex subset of a Banach space $E$. If $A: S \rightarrow E$ is a nonlinear contraction and $B: S \rightarrow E$ is completely continuous such that for each $x \in \partial(S), f_{x}(\partial(S)) \subseteq S$, then $A(u)+B(u)=u$ for some $u \in S$.

As another consequence, we have the following extension of a result of Cain and Nashed [5]. 
Corollary 2. Let $S$ be a convex and complete subset of $E$. Let $A: S \rightarrow E$ be a $\mathscr{P}$ contraction and $B: S \rightarrow E$ be a completely continuous mapping. If for each $x \in S, f_{x}$ satisfies (2) then $A(u)+B(u)=u$ for some $u \in S$.

Proof. It suffices to show that for each $p \in \mathscr{P}, p\left((I-A)^{-1} B(S)\right)$ is a bounded subset of reals. Now it follows by (10) that for all $x, y \in S$

$$
p(L(x)-L(y)) \leqq p(B(x)-B(y))+\alpha_{p} p(L(x)-L(y)),
$$

which implies that $p(L(x)-L(y)) \leqq\left(1-\alpha_{p}\right)^{-1} p(B(x)-B(y))$ and hence $L(S)=(I-A)^{-1} B(S)$ is bounded.

We wish to thank the referee for some useful comments.

\section{REFERENCES}

1. N. A. Assad, A fixed point theorem for weakly uniformly strict-contractions, Canad. Math. Bull., 16 (1973), 15-18.

2. N. A. Assad and W. A. Kirk, Fixed point theorems for set-valued mappings of contractive type, Pacific -J. Math., 43 (1972), 553-562.

3. F. F. Bonsall, Lectures on some fixed point theorems on functional analysis, Tata Inst. of Fundamental Research, Bombay, India, 1962.

4. D. W. Boyd and S. W. Wong, On nonlinear contractions, Proc. Amer. Math. Soc., 20 (1969), 458-464.

5. G. L. Cain, Jr. and M. Z. Nashed, Fixed points and stability for a sum of two operators in locally convex spaces, Pacific J. Math., 39 (1971), 581-592.

6. C. J. Himmelberg, Fixed points of compact multifunctions, J. Math. Anal. Appl., 38 (1972), 205-207.

7. M. A. Krasnoselskii, Two remarks on the method of successive approximations, Uspehi Mat. Nauk., 10 (1955), No. 1 (63), 123-127.

8. A. Meir and E. B. Keeler, A theorem on contraction mappings, J. Math. Anal. Appl., 28 (1969), 326-329.

9. M. Z. Nashed and J. S. W. Wong, Some variants of a fixed point theorem of Krasnoselskii and applications to non-linear integral equations, J. Math. Mech., 18 (1969), 767-777.

10. C. H. Su and V. M. Sehgal, Some fixed point theorems for non-expansive mappings in locally convex spaces, Bollettino U.M.I., 10 (1974), 598-601.

11. W. W. Taylor, Fixed point theorems for nonexpansive mapping in linear topological spaces, J. Math. Anal. Appl., 40 (1972), 164-173.

12. A. Tychonoff, Ein fixpunktsatz, Math. Ann., 111 (1935), 767-776.

Received May 21, 1975.

UNIVERSITY OF WYOMING

AND

UNIVERSITY OF NEWFOUNDLAND 



\section{PACIFIC JOURNAL OF MATHEMATICS}

\section{EDITORS}

RICHARD ARENS (Managing Editor)

University of California

Los Angeles, California 90024

\section{J. Dugundu}

Department of Mathematics University of Southern California Los Angeles, California 90007

D. Gilbarg and J. Milgram Stanford University Stanford, California 94305

\section{ASSOCIATE EDITORS}
E. F. BECKENBACH
B. H. NeumanN
F. WOLF
K. YoSHIDA

\section{SUPPORTING INSTITUTIONS}

UNIVERSITY OF BRITISH COLUMBIA CALIFORNIA INSTITUTE OF TECHNOLOGY

UNIVERSITY OF CALIFORNIA

MONTANA STATE UNIVERSITY

UNIVERSITY OF NEVADA

NEW MEXICO STATE UNIVERSITY

OREGON STATE UNIVERSITY

UNIVERSITY OF OREGON

OSAKA UNIVERSITY

\author{
UNIVERSITY OF SOUTHERN CALIFORNIA \\ STANFORD UNIVERSITY \\ UNIVERSITY OF HAWAII \\ UNIVERSITY OF TOKYO \\ UNIVERSITY OF UTAH \\ WASHINGTON STATE UNIVERSITY \\ UNIVERSITY OF WASHINGTON \\ AMERICAN MATHEMATICAL SOCIETY
}

The Supporting Institutions listed above contribute to the cost of publication of this Journal, but they are not owners or publishers and have no responsibility for its contents or policies.

Mathematical papers intended for publication in the Pacific Journal of Mathematics should be in typed form or offset-reproduced (not dittoed), double spaced with large margins. Underline Greek letters in red, German in green, and script in blue. The first paragraph or two must be capable of being used separately as a synopsis of the entire paper. Items of the bibliography should not be cited there unless absolutely necessary, in which case they must be identified by author and Journal, rather than by item number. Manuscripts, in duplicate, may be sent to any one of the four editors. Please classify according to the scheme of Math. Reviews, Index to Vol. 39. All other communications should be addressed to the managing editor, or Elaine Barth, University of California, Los Angeles, California, 90024.

100 reprints are provided free for each article, only if page charges have been substantially paid. Additional copies may be obtained at cost in multiples of 50 .

The Pacific Journal of Mathematics is issued monthly as of January 1966. Regular subscription rate: $\$ 72.00$ a year (6 Vols., 12 issues). Special rate: $\$ 36.00$ a year to individual members of supporting institutions.

Subscriptions, orders for back numbers, and changes of address should be sent to Pacific Journal of Mathematics, 103 Highland Boulevard, Berkeley, California, 94708.

PUBLISHED BY PACIFIC JOURNAL OF MATHEMATICS, A NON-PROFIT CORPORATION

Printed at Jerusalem Academic Press, POB 2390, Jerusalem, Israel.

$$
\begin{gathered}
\text { Copyright } 1976 \text { Pacific Journal of Mathematics } \\
\text { All Rights Reserved }
\end{gathered}
$$




\section{Pacific Journal of Mathematics}

Vol. 62, No. 2

February, 1976

Allan Russell Adler and Catarina Isabel Kiefe, Pseudofinite fields, procyclic

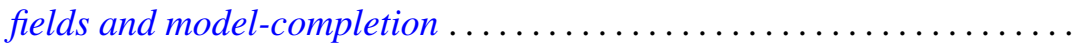

Christopher Allday, The stratification of compact connected Lie group

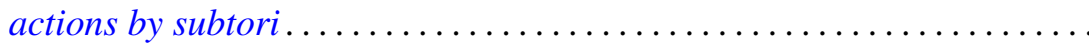

Martin Bartelt, Commutants of multipliers and translation operators .......

Herbert Stanley Bear, Jr., Ordered Gleason parts ..................

James Robert Boone, On irreducible spaces. II .....................

James Robert Boone, On the cardinality relationships between discrete

collections and open covers ............................

L. S. Dube, On finite Hankel transformation of generalized functions .......

Michael Freedman, Uniqueness theorems for taut submanifolds . . . . . . . . .

Shmuel Friedland and Raphael Loewy, Subspaces of symmetric matrices

containing matrices with a multiple first eigenvalue .............

Theodore William Gamelin, Uniform algebras spanned by Hartogs

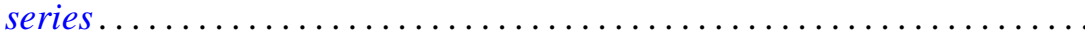

James Guyker, On partial isometries with no isometric part ............

Shigeru Hasegawa and Ryōtarō Satō, A general ratio ergodic theorem for

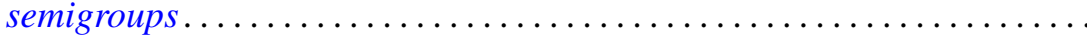

Nigel Kalton and G. V. Wood, Homomorphisms of group algebras with norm less than $\sqrt{2}$.

Thomas Laffey, On the structure of algebraic algebras...

Will Y. K. Lee, On a correctness class of the Bessel type differential operator $S_{\mu}$

Robert D. Little, Complex vector fields and divisible Chern classes ....

Kenneth Louden, Maximal quotient rings of ring extensions . .

Dieter Lutz, Scalar spectral operators, ordered $l^{\rho}$-direct sums, and the

counterexample of Kakutani-McCarthy . .

Ralph Tyrrell Rockafellar and Roger Jean-Baptiste Robert Wets, Stochastic

convex programming: singular multipliers and extended duality

singular multipliers and duality.

Edward Barry Saff and Richard Steven Varga, Geometric overconvergence of rational functions in unbounded domains ..........

Joel Linn Schiff, Isomorphisms between harmonic and P-harmonic Hardy

spaces on Riemann surfaces.

Virinda Mohan Sehgal and S. P. Singh, On a fixed point theorem of

Krasnoselskii for locally convex spaces.

Lewis Shilane, Filtered spaces admitting spectral sequence operations

Michel Smith, Generating large indecomposable continua . 